\title{
A Miniature L-slot Microstrip Printed Antenna for RFID
}

\author{
Mohamed Ihamji ${ }^{\star 1}$, El hassane Abdelmounim ${ }^{2}$, Jamal Zbitou ${ }^{3}$, Hamid Bennis ${ }^{4}$, \\ Mohamed Latrach ${ }^{5}$ \\ ${ }^{2}$ LASTI Laboratory, FST of Hassan 1st University, Settat, Morocco \\ ${ }^{3}$ LMEET Laboratory, FST of Hassan 1st University, Settat, Morocco \\ ${ }^{4}$ EST of Meknes, Moulay Ismail University, Meknes, Morocco \\ ${ }^{5}$ Microwave Group, ESEO Angers, France \\ ${ }^{*}$ Corresponding author, e-mail: mihamji@gmail.com
}

\begin{abstract}
This work presents a miniature microstrip antenna at $2.45 \mathrm{GHz}$ by using the slots technique. This microstrip antenna is fed by a CPW technique and designed for RFID reader system on FR4 substrate. A size reduction equal to $66.6 \%$ has been obtained compared to the conventional rectangular microstrip antenna. The total area of the final circuit is $19 \times 31 \mathrm{~mm}^{2}$. The validated antenna has good matching input impedance with a stable radiation pattern, a loss return of $-40 \mathrm{~dB}$, and a gain of $1.78 \mathrm{dBi}$, a prototype of the proposed antenna has been fabricated and measured.
\end{abstract}

Keywords: miniature antenna, microstrip antenna, RFID, L slot, CPW fed.

Copyright $@ 2018$ Universitas Ahmad Dahlan. All rights reserved.

\section{Introduction}

This paper presents the slot technique to miniaturize the microstrip antenna for RFID application. The abbreviation RFID stands for radio frequency identification, i.e. information carried by electromagnetic waves. An RFID system is generally composed from a reader, and one or more tags. The communication between the reader and the tag is achieved by modulated backscattering of the reader's carrier wave signal. The RFID system is used in many applications as transport, payment systems, access control, and logistic. Most RFID systems operate in either the low frequency region $(30-300 \mathrm{kHz})$, the high frequency band $(3-30 \mathrm{MHz})$, the ultra-high-frequency band $(300 \mathrm{MHz}-3 \mathrm{GHz})$, or in the microwave band $(3 \mathrm{GHz}-40 \mathrm{GHz})[1-6]$.

The microstrip antennas are widely used because of their good characteristics; they are low-profile, low weight, ease of fabrication, and mechanically robust. They are composed of three parts which are radiating element, substrate and ground, and can be designed on many structure shapes such as rectangular, elliptic, circular and triangular, etc. Rectangular patch is the basic and the most used microstrip antenna in wireless communication $[7,8]$.

The RFID antennas must be designed on small size and light weight structures. One of the techniques used to design a miniature antenna is the use of the slots technique; this technique is based in the use of certain approaches to manipulate the current distribution of the structure to change its resonant frequency [9-26].

In this paper, a novel design of a miniature low cost microstrip antenna is proposed at frequency of $2.45 \mathrm{GHz}$, this antenna is designed by using the symmetric L-slots inside the patch with the CPW (Coplanar Wave Guide) fed. The final circuit is validated by optimization methods integrated in CST-MW Studio; and realized with conventional Printed Circuit Board (PCB) techniques.

\section{Research Method}

The structure of the proposed antenna is a rectangular radiating patch as shown in Figure 1, and fed by a 50 ohms Coplanar Wave Guide line. This antenna uses an FR4 substrate with dielectric constant $\varepsilon r=4.4$, loss tangent $\tan \delta=0.025$, thickness $h=1.58 \mathrm{~mm}$, and metal thickness $\mathrm{t}=0.035 \mathrm{~mm}$. 


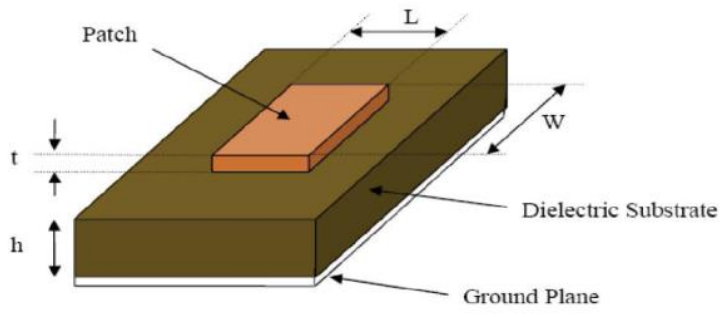

Figure 1. Patch antenna configuration

\subsection{Conventional microstrip antenna}

Conventional microstrip antenna has the length $L$ and the width $W$, which are related to the resonant frequency, to the permittivity and to the thickness of substrate; this length and width can be calculated, theoretically by the following conventional equations discussed in [27]:

$$
\begin{aligned}
& W=\frac{c}{2 f \sqrt{\frac{\varepsilon_{r}+1}{2}}} \\
& L=L_{\text {eff }}-2 \times \Delta L
\end{aligned}
$$

where $c$ is the speed of light, $f$ is the resonant frequency and $\varepsilon_{r}$ is the substrate's dielectric constant. $L_{\text {eff }}$ is the effective length given by:

$$
L_{e f f}=\frac{c}{2 f \sqrt{e f f}}
$$

and $\Delta L$ is the length extension, given by:

$$
\Delta L=0.412 h \frac{\left(\varepsilon_{e f f}+0.3\right) \times\left(\frac{W}{h}+0.264\right)}{\left(\varepsilon_{e f f}-0.258\right) \times\left(\frac{W}{h}+0.8\right)}
$$

where, $h$ is the height of substrate and $\varepsilon_{\text {eff }}$ is the effective dielectric constant which can be determined by:

$$
\varepsilon_{\text {reff }}=\frac{\varepsilon_{r}+1}{2}+\frac{\varepsilon_{r}-1}{2}\left(1+12\left(\frac{h}{W}\right)\right)^{-\frac{1}{2}}
$$

In this case, the dimensions of the conventional patch antenna at frequency $2.45 \mathrm{GHz}$ are: $\mathrm{L}=26.86 \mathrm{~mm}, \mathrm{~W}=37 \mathrm{~mm}$.

\subsection{Microstrip antenna with slots technique}

The $L$ slots are inserted into the microstrip antenna in order to modify the resonance frequency, by forcing the current to flow through a long path around the slots. Four symmetric L-slots are inserted inside the patch with the length Ls1 and Ls2, and the width Ws, as shown in Figure 2. The microstrip antenna with the L-slots has the length $L$ and the width $W$ which are dependent on the resonant frequency as shown in equation (1). It is connected to a Coplanar Wave Guide line with the width Wf and the length Lf. The length substrate Lsub is defined by 
the patch length $L$ and fed length $L f$. The width subtrate Wsub is determinated by the coplanar wave guide width Wcpw and adjusted to meet the good impedance matching and correct gain. The distance from the patch to the substrate edge is slightly larger, at least $3^{*}$ substrate thickness, to reduce fringe effects. Figure 2 illustrates the face of the antenna. The following table indicates the dimensions of the proposed antenna as shown in Table 1.

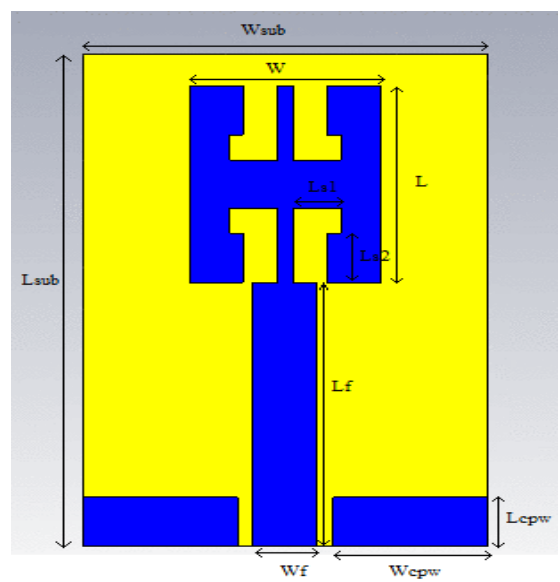

Figure 2. Geometry of the proposed antenna: Top Face

Table 1. Antenna Dimensions

\begin{tabular}{cc}
\hline Antenna Dimensions & Optimized Value $(\mathrm{mm})$ \\
\hline L & 12.4 \\
W & 9 \\
Lsub & 31 \\
Wsub & 19 \\
Lf & 16.6 \\
Wf & 3 \\
Ls1 & 3.1 \\
Ls2 & 2.25 \\
\hline
\end{tabular}

\section{Results and Analysis}

A new antenna structure with four symmetric L-slots and Coplanar Wave Guide fed is proposed. The width and length value of patch antenna are optimized on CST EM solver. As shown in Figure 3, the size characteristics of the proposed antenna structure, WsubxLsub $=19 \times 31 \mathrm{~mm}^{2}$, is very small compared to the conventional rectangular microstrip antenna at the operating frequency, WsubxLsub $=39 \times 45.21 \mathrm{~mm}^{2}$.

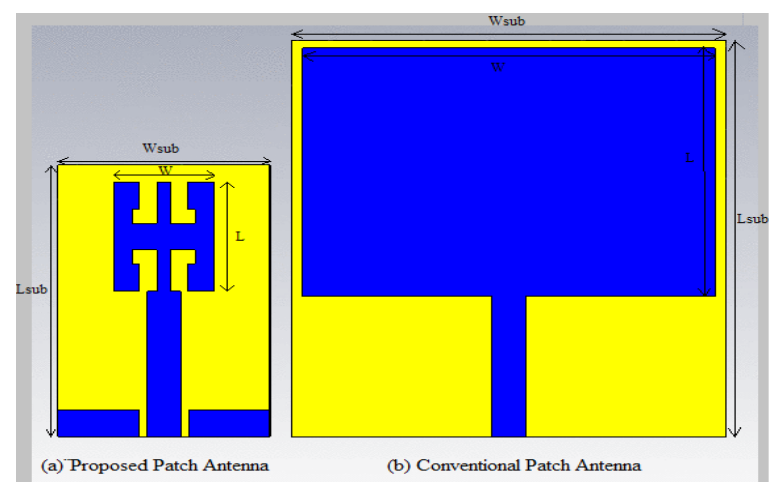

Figure 3. (a) Proposed Patch Antenna, (b) Conventional Patch Antenna 


\subsection{Simulation results}

Figure 4 shows the return loss S11 result for the antenna, it has good matching input impedance at frequency $2.45 \mathrm{GHz}$. A return loss (S11) equal to $-40 \mathrm{~dB}$ is obtained with this antenna. The bandwidth value is approximately $235 \mathrm{MHz}$. The gain and directivity are respectively $1.78 \mathrm{dBi}$ and $1.87 \mathrm{~dB}$. Figure 5 illustrates the $2 \mathrm{D}$ radiation patterns at E-plane and $\mathrm{H}$-plane respectively. The proposed antenna has an omni-directional radiation pattern for $\mathrm{E}$ plane. The angular width is 86.2 degree at $2.45 \mathrm{GHz}$. Figure 6 illustrates the surface current distribution of the proposed antenna at $2.45 \mathrm{GHz}$. A maximum current is observed around the $\mathrm{L}$ slots placed at low side, and around the feed line.

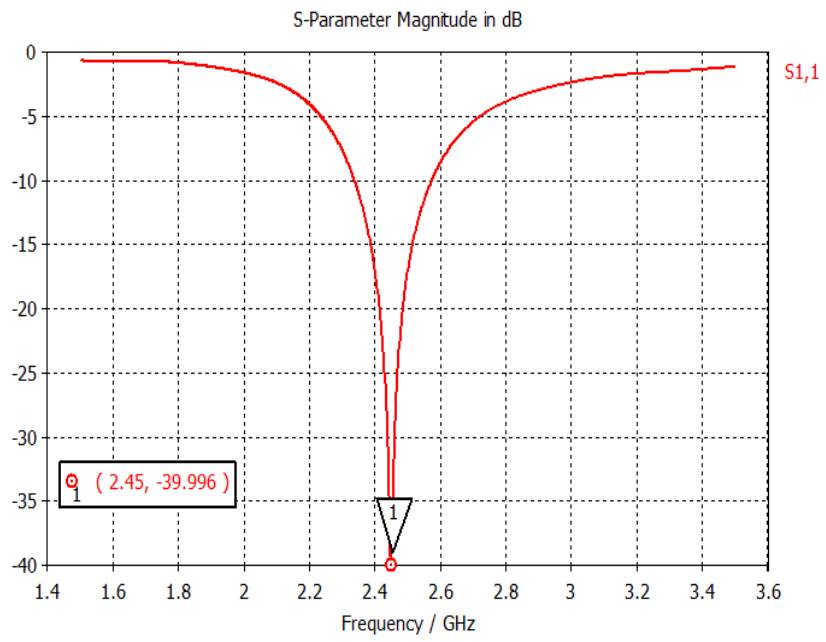

Figure 4. Return loss (S11) value of the proposed antenna

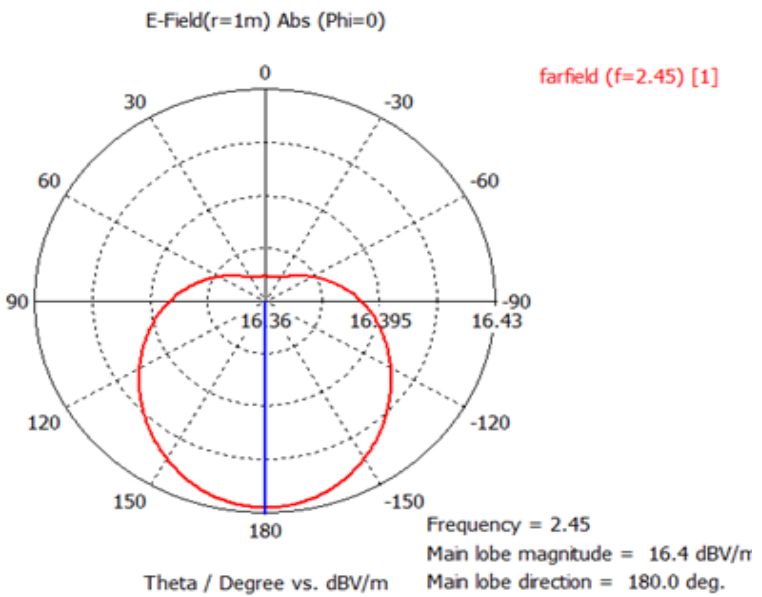

(a)

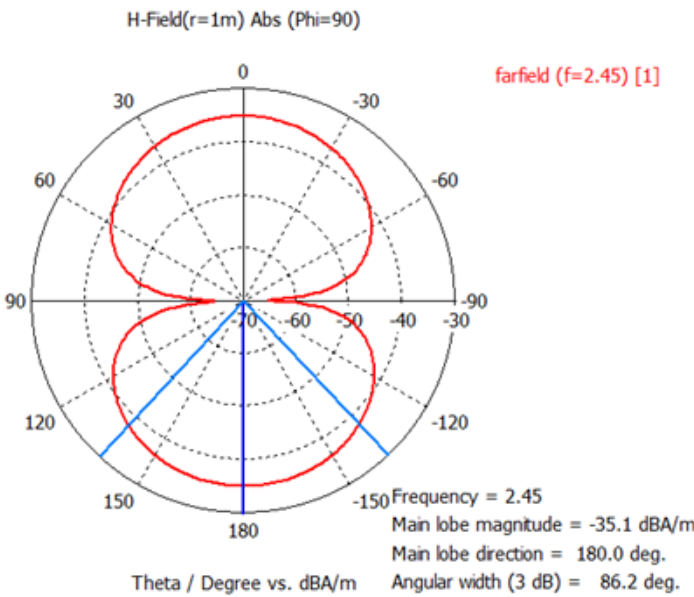

(b)

Figure 5. 2D radiation patterns of the proposed antenna in E-plane (a) and $\mathrm{H}$-plane (b)

The simulated gain versus frequency is illustrated in Figure 7 , the peak gain is $1.78 \mathrm{dBi}$ at $2.45 \mathrm{GHz}$. The results obtained by CST_MW are compared to ADS, a 3D electromagnetic solver. Figure 8 illustrates the return losses obtained by simulation. These results present an acceptance agreement between CST-MW and ADS, results obtained by CST are more pessimist than ADS results. 


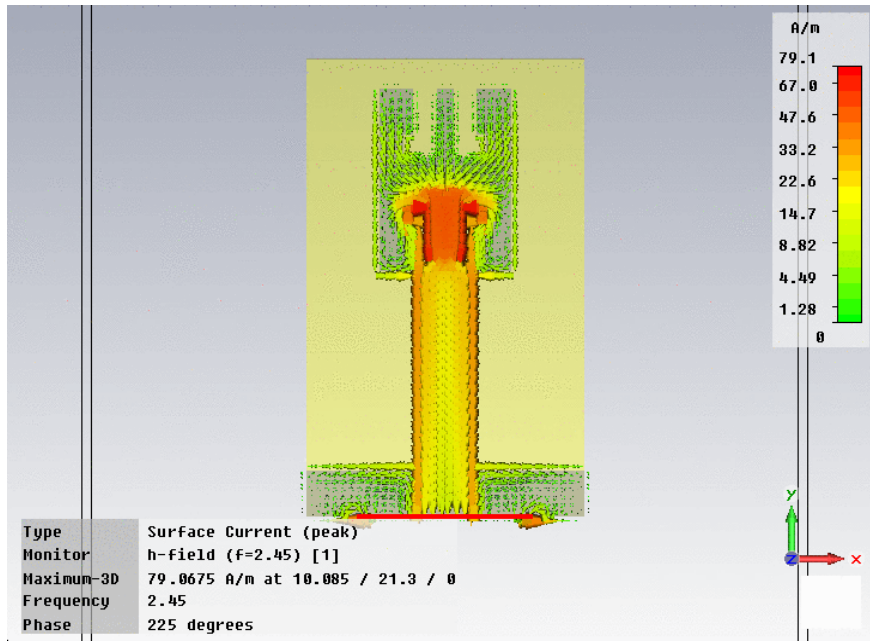

Figure 6. Surface current distributions of the proposed antenna

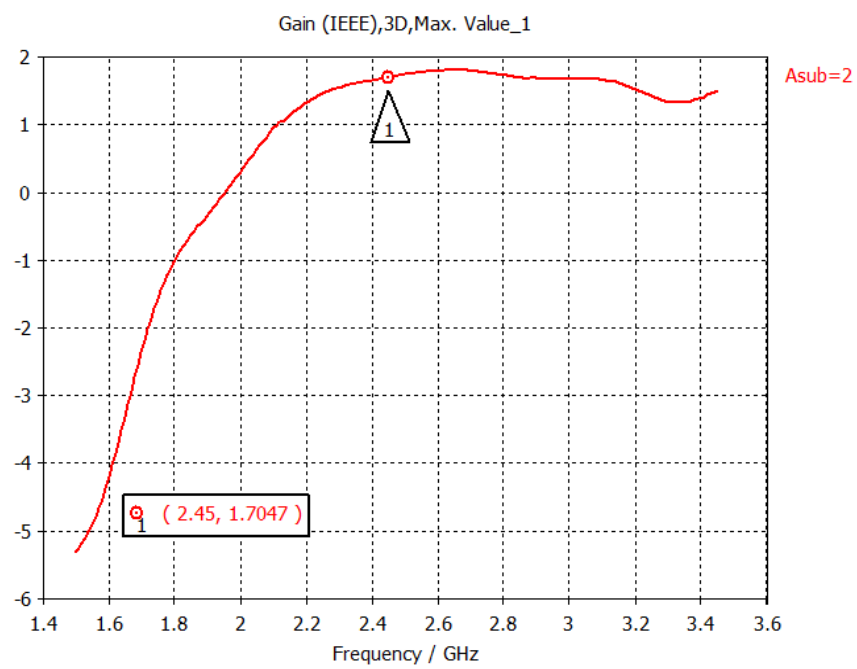

Figure 7. Gain versus frequency of the proposed antenna

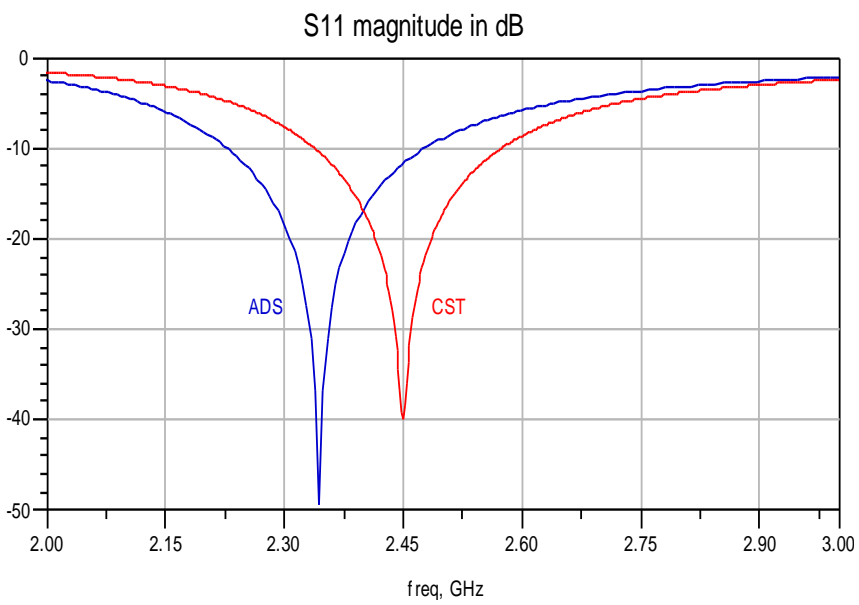

Figure 8. Comparison between return losses obtained by CST-MW and ADS 
The results obtained of the proposed antenna, summarized in Table 2, show a good return loss S11, and a good bandwidth. The gain and directivity value are acceptable for RFID applications. A CPW-feed has a high bandwidth, compared to the microstrip line feed with a conventional microstrip antenna, as shown in Table 2.

Table 2. Result Comparison between Proposed Antenna and Conventional Patch with Microstrip Fed

\begin{tabular}{cccc}
\hline Patch Antenna 2.45 GHz & $\mathrm{S} 11(\mathrm{~dB})$ & Bandwidth $(\mathrm{MHz})$ & Gain $(\mathrm{dB})$ \\
\hline Conventional antenna & -43.5 & 60 & 1.76 \\
Proposed Ante nna & -40 & 235 & 1.78 \\
\hline
\end{tabular}

\subsection{Experimental results}

A prototype of the proposed antenna has been realized to check the performance of the simulation results obtained by CST-MW and ADS, as shown in Figure 9. Figure 10 shows the simulated and measured return loss of the antenna. The results summarized in Table 3 , show good agreement with a return loss of approximately $-10 \mathrm{~dB}$ at frequency $2.45 \mathrm{GHz}$.

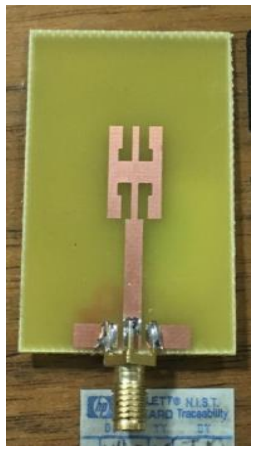

Figure 9. The antenna prototype achieved

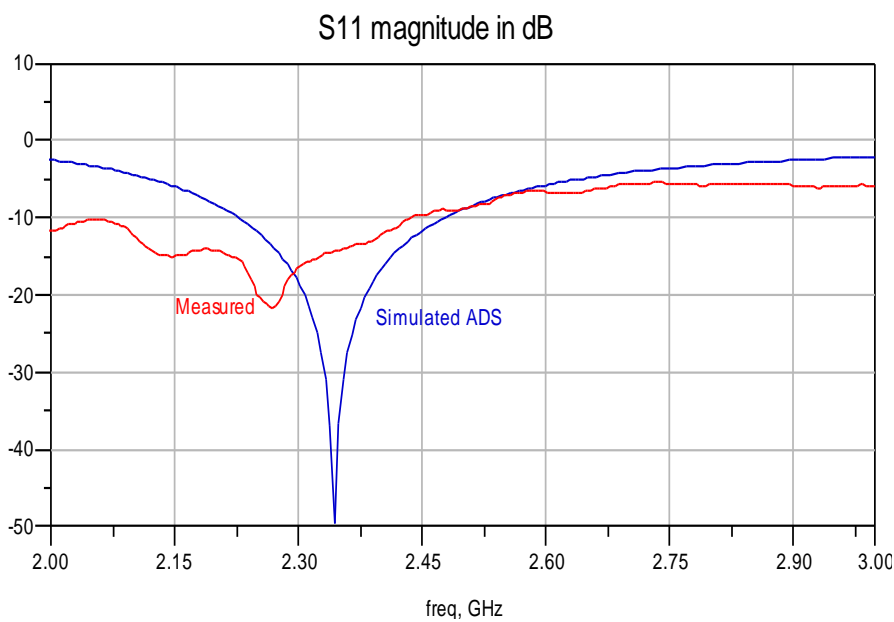

Figure 10. Measured and simulated return loss of the proposed antenna

Table 3. Resume of Simulated and Measured Results

\begin{tabular}{ccccc}
\hline Frequency & S11 $(\mathrm{dB})$ & $\mathrm{S} 11(\mathrm{~dB})$ & Bandwidth $(\mathrm{MHz})$ & Bandwidth $(\mathrm{MHz})$ \\
\hline & Simulated & Measured & Simulated & Measured \\
$2.45 \mathrm{GHz}$ & -40 & -10.0 & 235 & 400 \\
\hline
\end{tabular}


The results obtained of the proposed antenna, summarized in Table 4 and Table 5, present a good miniaturization of the antenna dimensions. As shown in Table 5, The total size reduction obtained, compared to some antennas that operate at the same frequency of $2.45 \mathrm{GHz}$, is for example equal to $66.6 \%$ for the conventional rectangular microstrip antenna, $56.3 \%$ for the compact cpw-fed dual-band uniplanar antenna, realized by Ahmed and al [28], $54.5 \%$ for the dual band metamaterial printed antenna based on CSRR, obtained by Abdelhadi and al [29], 49.0\% for the miniature planar microstrip antenna using DGS, realized by Er-rebyiy and al [30], and $49.0 \%$ for the compact low cost dual-band slot antenna, realized in a previous work [31].

Table 4. Patch Size Result Comparison Between Proposed Antenna And Others Antennas

\begin{tabular}{cccc}
\hline Patch Antenna 2.45 GHz & $\mathrm{W}(\mathrm{mm})$ & $\mathrm{L}(\mathrm{mm})$ & Patch size reduction $(\mathrm{WxL})$ \\
\hline Conventional antenna & 37 & 28.3 & \\
Proposed Antenna & 9 & 12.4 & $89.3 \%$ \\
\hline
\end{tabular}

Table 5. Total Size Comparison Between Proposed Antenna And Others Antennas

\begin{tabular}{cccc}
\hline Patch Antenna 2.45 GHz & $\begin{array}{c}\text { Wsub } \\
(\mathrm{mm})\end{array}$ & Lsub (mm) & $\begin{array}{c}\text { Total size reduction } \\
\text { (Wsub xLsub) }\end{array}$ \\
\hline Proposed Antenna & 19 & 31 & $66.6 \%$ \\
Conventional antenna & 39 & 45.2 & $56.3 \%$ \\
Compact CPW-Fed Dual Band Uniplanar antenna [28] & 30 & 45 & $54.5 \%$ \\
Dual Band Metamaterial Printed Antenna [29] & 36 & 36 & $49.0 \%$ \\
Miniature Planar Microstrip Antenna Using DGS [30] & 34 & 34 & $49.0 \%$ \\
Compact Low Cost Dual-Band Slot Antenna [31] & 35 & 33 & $\%$ \\
\hline
\end{tabular}

\section{Conclusion}

This paper presents a new rectangular microstrip antenna with symmetric L-slots and CPW fed. A size reduction of antenna dimension equal to $66.6 \%$ has been obtained compared to conventional microstrip antenna. It provides appropriate characteristics, with a return loss equal to $-10 \mathrm{~dB}$, a bandwidth of $400 \mathrm{MHz}$, the value of theoretical directivity is $1.87 \mathrm{~dB}$, and that of theoretical gain is $1.78 \mathrm{dBi}$. The antenna has been designed on a standard FR4 substrate and realized with conventional Printed Circuit Board (PCB) techniques.

\section{Acknowledgment}

We thank Mr. Mohamed Latrach Professor in ESEO, engineering institute in Angers, France, for allowing us to use all the equipment and EM solvers available in his laboratory.

\section{References}

[1] Nasimuddin. Microstrip Antennas. InTech Janeza Trdine 9, 51000 Rijeka, Croatia, 2011.

[2] Debatosh Guha, Yahia MM. Microstrip and Printed Antennas: New Trends, Techniques and Applications. John Wiley \& Sons, Ltd. Antar_ 2011.

[3] Antony Ghiotto. Tag UHF RFID antenna design, application by jet of material. PhD Thesis. Institut polytechnique Grenoble France, 2008.

[4] Nathan D Reynolds. Long range ultra-high frequency (UHF) radio frequency identification (RFID) antenna design. PhD Thesis. Faculty of Purdue University Fort Wayne, Indiana. 2012.

[5] Klaus Finkenzeller. RFID Handbook Fundamentals and Applications in Contactless Smart Cards, Radio Frequency Identification and Near-field Communication. Third edition. Giesecke \& Devrient GmbH. Munich. Germany. 2010.

[6] Mélusine Pigeon. Design of ultra-compact antennas based on metamaterials, application to the fabrication of a miniature GNSS antenna. PhD Thesis. Institut National Polytechnique Toulouse France. 2011.

[7] K Nithisopa, J Nakasuwan1, N Songthanapitak, N Anantrasirichai, T Wakabayashi. Design CPW fed slot antenna for wideband applications. Piers online. 2007; 3(7).

[8] T Deleruyelle, P Pannier, E Bergeret, S Bourdel. Dual band UHF and microwave RFID antenna. Proceedings of the 38th European microwave conference. 2008.

[9] Monti, L Catarinucci, L Tarricone. Compact Microstrip Antenna for RFID Applications. Progress in Electromagnetics Research Letters. 2009; 8: 191,199. 
[10] Nazish Irfan, Mustapha CE Yagoub, Khelifa Hettak. Design of a microstrip-line-fed inset patch antenna for RFID Applications. IACSIT International Journal of Engineering and Technology. 2012; 4(5).

[11] S.Anscy. Slot microstrip antenna for 2.4GHz RFID reader application. Department of Electronics and Communication Engineering Karunya University. International Journal of Advanced Research in Electronics and Communication Engineering (IJARECE). 2013; 2(5).

[12] Chandrappa DN, Ambresh PA, Vani RM, PV Hunagund. Multi-slots reconfigurable microstrip antenna with capacitive loading technique. International Journal of Innovative Research in Computer and Communication Engineering. 2014; 2(1).

[13] Mohamed Ihamji, Elhassane Abdelmounim, Jamal Zbitou, Hamid Bennis, Mohamed Latrach. Novel Design of a Miniature Fractal Microstrip CPW Fed Antenna for RFID Reader. IEEE Conference Publications. The International Conference on Wireless Networks and Mobile Communications (WINCOM). 2016.

[14] Abdelhak Ferchichi, Gharsallah Ali. Novel Small Sierpenski Antennas. International Journal of Electrical and Computer Engineering (IJECE). 2013; 3(4).

[15] Chaouki Guesmi, Abdelhak Ferchichi, Ali Gharsallah. A Modified Fractal Bow Tie Antenna for an RFID Reader. International Journal of Electrical and Computer Engineering (IJECE). 2014; 4(3).

[16] A Balanis. Antenna Theory Analysis and Design. 2nd edition John Wiley \& Sons, Inc. 2003.

[17] A Reha, A El Amri, O Benhmammouch, A Oulad Said, A El Ouadih, M Bouchouirbat. CPW-fed H-tree fractal antenna for WLAN, WIMAX, RFID, C-band, HiperLAN, and UWB applications. International Journal Microwave Wireless Technology. 2015: 1-8.

[18] Nawel Seladji-Hassaine, Fethi Tariq Bendimerad. Miniaturized Dual Band Triangular Microstrip Antenna with Sierpinski Fractal Ground. International Journal of Microwave and Optical Technology. 2016; 11(5).

[19] Issam Zahraoui, Ahmed Errkik, Elhassane Abdelmounim, Hamid Bennis, Larbi El Abdellaoui, Angel Sanchez Mediavilla. A New Design of a CPW Fed Triple-Band for GPS, UMTS and WiMAX Applications. International Journal on Communications Antenna and Propagation. 2015; 5(6).

[20] Ikram Tabakh, Mohamed Jorio, Najiba El Amrani El Idrissi, Tomader Mazri. Design and Optimization of a New Slotted Patch Antenna for RFID Applications. International Journal on Communications Antenna and Propagation. 2016; 6(1).

[21] Ahmed El Hamraoui, El Hassane Abdelmounim, Jamal Zbitou, Ahmed Errkik, Hamid Bennis, Mohamed Latrach. A Dual-Band Microstrip Slot Antenna Reader for UHF and Microwave RFID Applications. TELKOMNIKA (Telecommunication, Computing, Electronics and Control) Journal. 2018; 16(1): 94-101.

[22] Abdelhadi Ennajih, Jamal Zbitou, Mohamed Latrach, Ahmed Errkik, Larbi EL Abdellaoui, Abdelali Tajmouati. New Miniature Microstrip Antenna Based on Metamaterial for RFID Applications. TELKOMNIKA (Telecommunication, Computing, Electronics and Control) Journal. 2018; 16(1): 174181.

[23] Evizal Evizal, Tharek Abdul Rahman, Sharul Kamal Abdul Rahim. UHF RFID Tag Antenna for Vehicle License Plate Number. TELKOMNIKA (Telecommunication, Computing, Electronics and Control) Journal. 2013; 11(2).

[24] Mohamed Ihamji, Elhassane Abdelmounim, Hamid Bennis, Mostafa Hefnawi, Mohamed Latrach. Design of Compact Tri-Band Fractal Antenna for RFID Readers. International Journal of Electrical and Computer Engineering (IJECE). 2017; 7(1).

[25] AF Morabito, AR Laganà, $T$ Isernia. Optimizing power transmission in given target areas in the presence of protection requirements. IEEE Antennas and Wireless Propagation Letters, 2015; 14: 4447.

[26] AF Morabito. Synthesis of maximum-efficiency beam arrays via convex programming and compressive sensing. IEEE Antennas and Wireless Propagation Letters. 2017; 16: 2404-2407.

[27] DG Fang. Antenna Theory and Microstrip Antennas. Taylor and Francis Group, LLC. 2010: 103.

[28] Ahmed El Hamraoui, El Hassane Abdelmounim, Jamal Zbitou, Laarbi Elabdellaoui, Hamid Bennis, Mohamed Latrach. A New Compact CPW-Fed Dual-Band Uniplanar Antenna for RFID Applications. TELKOMNIKA (Telecommunication, Computing, Electronics and Control) Journal. 2018; 16(1): 102109.

[29] Abdelhadi ennajih, Jamal Zbitou, Mohamed Latrach, Ahmed Errkik, Larbi El Abdellaoui, Abdelali Tajmouati. Dual Band Metamaterial Printed Antenna Based on CSRR for RFID Applications. International Journal of Microwave and Optical Technology. 2017; 12(2).

[30] R Er-rebyiy, J Zbitou, M Latrach, A Tajmouati, A Errkik, L EL Abdellaoui. New Miniature Planar Microstrip Antenna Using DGS for ISM applications. TELKOMNIKA (Telecommunication, Computing, Electronics and Control) Journal. 2017; 15(3).

[31] A El Hamraoui, EH Abdelmounim, J Zbitou, H Bennis, M Latrach. A compact low cost dual-band slot antenna for RFID readers. International Journal of Microwave and Optical Technology. 2018; 13(1). 